\title{
Plant biotechnology: aspects of its application in industry
}

\author{
B. J. Miflin \\ Ciba-Geigy Seeds, CIBA-GEIGY, Postfach, CH-4002 Basle, Switzerland
}

\begin{abstract}
Synopsis
Plant biotechnology can serve industrial concerns in two ways; it can lead to new products and to new ways of producing an existing product (i.e. 'processes'). The technology can be used in any business involved in using or selling plant products. In the agricultural input business molecular genetics is having most effect on the introduction of new variation into crop plants. The first products are likely to involve the introduction of insect and disease resistance and herbicide tolerance; some genes transferred will change product quality. Future applications will involve the control of more complex traits. Biotechnology will also enhance plant breeding via improved technologies (e.g. RFLPs and tissue culture); also the production of hybrids is likely to be enhanced and extended. Early products will also include the production of rDNA microbial products for control of pests and diseases.

Of considerable concern to businesses is whether or not they can make sufficient financial return on plant biotechnology. The reasons behind this concern are the time it takes to introduce a product to the market; the expenditure on meeting regulatory requirements; the overall level of public acceptance of the products and the level of return from the farmer. To ensure a fair return on investment there also needs to be a secure structure of intellectual property protection (patents, plant breeders rights, etc.). Continued success in the application of plant science to agricultural improvement depends on a proper economic environment as well as the advancement of the science.
\end{abstract}

\section{Introduction}

Plant biotechnology can make two direct contributions to the agricultural industry; it can improve processes to produce the existing type of products and it can lead to a new types of products. This is true for industries involved in both the input and output side of agriculture.

Serving the input side of agriculture are the industries involved in the production of plant protection products, seeds and fertilisers. In the field of plant protection, biotechnology can give rise to recombinant microorganisms, such as Bacillus thuringiensis, which can act as biological protection agents against pests and diseases. Additionally, biotechnology can contribute to the development of conventional plant protection chemicals by the identification and cloning of genes involved in the production of enzymes associated with actual or potential target sites for chemical action. This in turn can lead to new knowledge and potential new screening mechanisms. Similarly, monoclonal antibodies can be used as diagnostics for the presence of disease and lead to more intelligent and effective spraying regimes. Perhaps the most important carrier of the effects of the new biotechnology to the market place will be the seed industry. This is not surprising since the major part of the "new biotechnology' is involved in methods of isolating, modifying and transferring genes. I will deal with the impact on the seed industry in more detail below. The final input is plant nutrition. Some impact has been made in this area through the selection, production and sale of improved strains of rhizobia for inoculating legumes. However, the originally much trumpeted possibility of nitrogen-fixing cereals, despite a 
recent surge of interest, remains as far off from the market place as it was fifteen years ago.

Plants are the raw materials for many industrial processes. The introduction of novel traits into plants has the potential to improve many of the industrial processes in which they are used. This is true both for the food and feed industries as well as for the industrial uses of plants. So far not many of the potentials have been realised but, nevertheless, some of the first products in this area are moving towards the market.

\section{Plant biotechnology in the seed industry}

Plant breeding was profoundly influenced by the findings of Mendel and the development of the science of genetics. Over the past 90 years it has been immensely successful. But, despite this success, there are a number of limitations.

Conventional breeding cannot introduce traits that are not present, or which cannot be generated by mutation and selection, in the species in question or in species with which it can be crossed. The genetic basis of most desired traits is unknown. The genetic map of maize at the beginning of the 1980s was based mainly on mutations and traits of no conceivable commercial importance. In the main, the plant breeder has to infer the genotype from the phenotype; this inference is greatly confounded by the large interaction with the environment (see the paper by Innes in this volume). Screening technologies can be expensive and tedious. Thus there is a considerable potential for plant biotechnology to contribute novel and better solutions. Figure 1 represents the type of decision tree that a generalised plant breeder could face in trying to improve his crop for a given trait. At many stages the breeder might be faced with a difficult or impossible problem, in some cases biotechnology offers a potential solution. This is particularly true where the variation required does not exist within the species, or its sexually compatible relatives, but does exist somewhere else in the biological kingdom. For example, the inability of many crops to withstand damage caused by Lepidopteran pests can be combatted by transferring the gene(s) for delta-endotoxin synthesis present in the bacterium Bacillus thuringiensis. Demonstrated field efficiency of this transfer has been achieved in tobacco, tomato and cotton (Perlach et al. 1990).

Many of the problems of understanding the genetics of important traits is and will continue to be improved by using RFLP technology (see paper by Tanksley in this volume). This technology will aid tremendously in incorporating traits that are controlled by several genes into elite material. RFLP technology also can and will enable breeders to backcross simply inherited traits from exotic material much more effectively. The problem in the past has not been to incorporate the traits but rather to eliminate the phenomenon of 'linkage drag'. This brings along with the favourable trait large proportions of genetic material which are linked to that trait. If this linked genetic material does not have any readily identifiable phenotypic markers it is difficult to select against. However, leaving it in the elite line may result in lowered performance of the elite line. Retrospective studies by Young \& Tanksley (1989) have shown that large amounts of linked genetic material from the donor line have not been eliminated in many backcrossing programmes.

It is one thing to identify where plant biotechnology may be useful in a breeding programme, it is something entirely different to decide if using the technology will 
STEPS IN

PLANT BREEDING

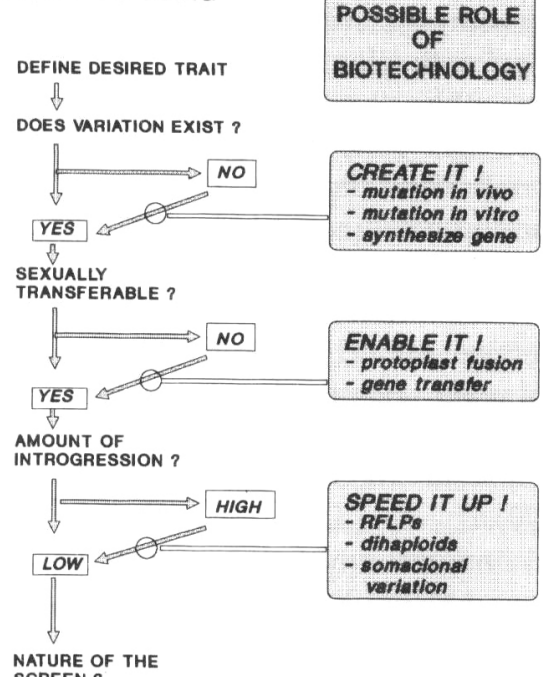
SCREEN ?
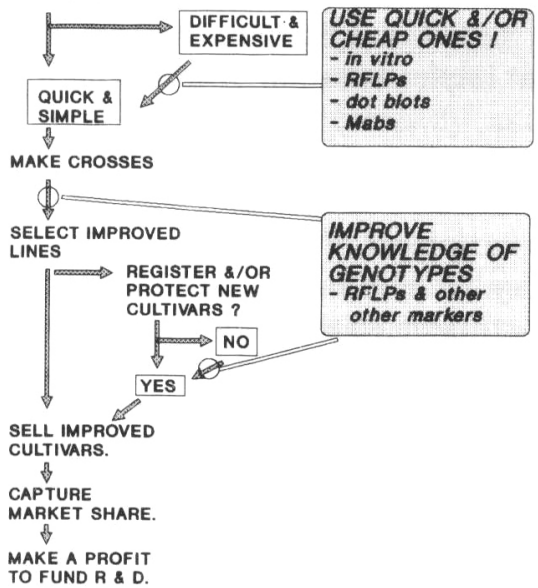

Figure 1. Decision tree for a plant breeder trying to improve a crop for a given trait and points at which biotechnology may make an impact.

pay off commercially. In the long term, industry will not be interested in investing in plant breeding and biotechnology unless it allows industry to give the people who invest in it a return on that investment. To date there has been virtually no return on investment in plant biotechnology despite the vast amount of funds invested in it. One consulting company has calculated that about US $\$ 2.5$ billion have so far been invested by multinationals and small start-up companies. In many cases small firms have been unable to sustain the endeavour and have had repeatedly to search for new funds. These have not always been forthcoming and the companies have either folded or merged with others. Likewise, many major company investors have left the field. In particular, most of the major oil companies have exited. Others, particularly agriculturally based companies, appear to have a longer-term commit- 
ment. However, it is unreasonable to expect that this will continue indefinitely without adequate returns being generated.

A measure of disillusion with plant biotechnology and plant science in general has also been seen in the public sector. This has probably been most dramatic in England where the AFRC has gone through a large cut in resources. The Plant Breeding Institute at Cambridge, once the centre of the AFRC's effort and the premier institution combining breeding and plant biotechnology in the world (either public or private), has been divided up and the breeding part sold. In the U.S.A., critics who published the Biotechnology's Bitter Harvest (Goldburg et al. 1990) petition politicians to reduce public research spending on certain areas of plant biotechnology. Individual plant scientists have also written public statements criticising the spending of public money on this field and also criticised the role of scientists in facilitating the development and application of the technology to agriculture (Crouch 1990; Gates 1990).

This critical social and financial environment threatens investment in both public and private plant science and technology. Furthermore, if this technology brings the benefits expected, limiting investment could severely limit society's efforts to feed an ever-expanding population. I would therefore like to discuss the ways in which the recent advances in plant science are likely to move to the market and some of the blocks that might prevent implementation of the technology.

\section{Science into practice}

Figure 2 summarises the movement of science into practice in society. Science per se is concerned with discovery but with an implied belief that knowledge brings potential benefits. Many commentators on science, for example Medewar (1984), see science
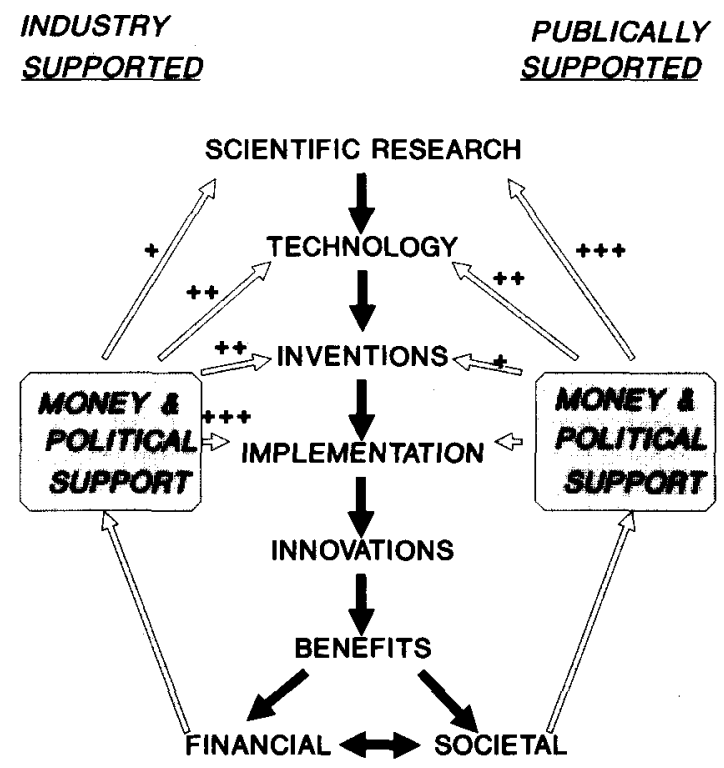

Figure 2. The path of discoveries from scientific research to the marketplace and feedback controls operating upon it. 
as being carried out by ordinary people motivated by curiosity and a desire to make the world a better place to live in. Science can in general only be turned into benefits through the development of technology (i.e. the development of new tools and products). Once developed, technological innovations have to be implemented and accepted by society. To be accepted, they need to bring perceived benefits to society and, if society wishes to have a flow of new products from technology, a way has to be achieved to give reward to those that carry out the research and development. The mechanisms by which this may be achieved may differ between the private and public sector but the underlying principle is the same. Besides financial returns, there must be political support for the technology, because without this it is difficult for the champions of the technology to get new projects off the ground, either in industry or in the public sector. The whole chain of events also cannot occur unless there is a cadre of dedicated, trained and able people to carry it out. The motivation of young people to enter the field is usually vitally affected by the esteem in which it is held by the public. Thus the path of development from a scientific discovery to the arrival of new useful products in the market place is subject to a range of feedbacks.

The way in which these feedbacks occur is also shown in Figure 2. The roles of the public and private sectors differ in their responsibilities for the different parts of the chain. Basic science is seen as the province of the public sector, although industry does make a contribution (for example, my company totally funds the Friedrich Miescher Institute in Basle which is dedicated to research in basic biology). The development of technology and the making of inventions occurs in both areas, although, despite the increasing number of patents being applied for by public sector institutions, the majority of technology inventions come from industry. Where industry plays the largest part is in the implementation of inventions. Without implementation there is no innovation and inventions stay on the drawing board or in the patent literature. It is this area where the Japanese have been particularly strong and have brought to the market many inventions made elsewhere (e.g. the transistor). In the seed industry, the public sector in Europe and the U.S.A. has largely withdrawn from producing finished varieties - the essential final step for implementing most plant biotechnology. Only in Japan, where the seed industry is largely government controlled, and in the institutes of the CGIAR (see the paper by Sawyer) are there large-scale publically funded efforts to implement the inventions of plant breeding and biotechnology. The conclusion is that in Europe and North America at least, the products of the genetic revolution in plants will chiefly reach the market via private industry.

\section{The blocks on implementation}

There are three major areas which have to be satisfied in ensuring the implementation of biotechnology by industry; financial benefits, a rational regulatory environment and public acceptance. The latter two areas also apply to introduction of products from the public sector.

\section{Financial benefits}

These are affected by the structure of the industry and the way in which inventions are protected (so-called intellectual property protection). For example, in the Euro- 
pean seed business the return to the breeder of inbred varieties in Europe is through a royalty system. The overall royalty income available to breeders in the U.K. has been calculated as being about half the amount of money currently invested in the commercial breeding programmes in the U.K. Obviously, this situation cannot continue indefinitely. The farming industry and the society depending upon it has a choice between working out a way to ensure that the breeders receive a fair return on their efforts or eventually losing the value of the breeding effort that is currently improving cereal varieties. For example, Pioneer recently chose to close down a large part of their breeding programme for wheat in the U.S.A. because of insufficient return. Additionally, if these crops are to benefit from the efforts of biotechnology then clearly a means to give even more return to the inventor will have to be devised the alternative is that companies will cease to invest in technology improvement for inbred cultivars.

The ownership of varieties is determined through the various national systems on plant variety rights. In essence, these grant a breeder an intellectual property right for his new variety; other breeders may not obtain rights for the same or nearly identical varieties. This ensures that the royalties go to the breeder of a registered variety and that others cannot multiply that variety and claim it as their own. Patents, another intellectual property system, also work to give the inventor a fair return and to stimulate new inventions. These topics are dealt with in more detail in the paper by Byrne in this volume. In both cases the interests of society are supported by a system that stimulates investments to provide improved solutions to agricultural problems. Despite many criticisms, the patent system has worked well to ensure the development of new products for society.

\section{Regulations}

For the benefits of rDNA technology to come to the market place, the products must be tested and developed under current regulations and new regulations governing commercial release must be developed. Field testing of rDNA plants has occurred widely in Europe and the U.S.A. (with some 300 field tests to date) although there are some European countries where regulations are not yet in place or in which few tests have been held. So far these regulations seem to work well and do not provide any serious block to the development of rDNA plant products.

More importantly, if rDNA plants are to come to the market place, there is the need to develop regulations that govern the commercial release of products. As I have indicated, several products are not so far from the market. It is essential that any regulations produced are rationally based and make use of our existing body of knowledge. For example, recent proposed regulations governing the labelling of food would require products of inter-species gene transfer to be labelled as the product of genetic engineering. Many foods are already the result of inter-species gene transfer or of inter-species hybridisation. 'Take the case of wheat flour. Wheat is an hexaploid derived from a chance natural association of three genomes from different species. Furthermore, around half of the wheat grown today in Britain is derived from lines in which the short arm of chromosome 1 of the wheat B genome has been replaced by the short arm of chromosome 1 of rye (Secale cereale, a different genus). The advantage of this translocation is that it introduces genes for disease resistance and higher yield (Baum \& Appels 1991). It also introduces genes for 'sticky dough' which limits the use of these varieties for bread making. Neither the flour 
from this wheat, nor any products made from it have to be specially labelled under current or proposed legislation. However, if the recently published draft proposed guidelines for the U.K. (Anon 1990) are followed, then cultivars derived from the transfer of the defined favourable genes from rye through the isolation of those genes and their subsequent transformation into wheat will have to be labelled. This discrimination in favour of the crude transfer against the precise transfer does not seem rational. While I am strongly in favour of industry trying to meet the genuine needs of the public to know what is in their food, this case would involve information being given which makes a technical distinction on breeding methodology, the significance of which could be misunderstood. Much more important is that people should know what is in a product and if it differs in any way from what is traditional. However, the attention should focus on the product of the gene (i.e. protein or enzyme reaction) and not on the gene or on how it was introduced.

Further discussion of regulations and how they may affect the progress of products to the market place is in the paper by Beringer.

\section{Public perception}

If the products of plant molecular biology are to make a contribution to the market place, then they have to be accepted by the public. This means that their benefits have to outweigh any real or perceived risk. This acceptance is affected by the public's ability to judge and on the activities of critics, proponents and the media.

Benefits. Breeding has for the last ninety years been a story of the increasing precision and control over recombining genes in our crop plants to give increased performance. The result of this effort in our major crops has been a steady increase in yield potential. However, despite this success, many problems remain as indicated above particularly in handling the large number of genes in crop plants and in having sufficient variation available within the species. This difficulty can be considered in relation to having to protect crops against attacks from pests and diseases. Certain crop species are particularly susceptible to given pests and diseases. For example, cotton is heavily attacked by insects and requires large amounts of insecticides in order that it can be grown profitably in the U.S.A.; in contrast, sorghum and soybeans, even when grown in the same environment, require relatively little. If sources of pest tolerance exist in sexually crossable species these can then be bred into the crop but in many cases such sources of resistance are not present in the available gene pool. In this instance, the breeders' art can contribute little to the solution of the problem.

rDNA technology offers a contribution by its ability to isolate and transfer genes by means not limited by sexual compatibility. This means that a whole new range of variation is available to plant breeders. Thus the problem in cotton mentioned above can at least be partly overcome by introducing genes producing proteins toxic to the insect. Such modified cotton plants are effective in combatting insect attack. Adding such remedies to the plant has several advantages in ease of use for the farmer and in ensuring the remedy is constrained, so that it is only exposed to the target pest and not to other insects in the environment that do not feed off the crop plant.

Overall, the remedies provided via plant breeding, aided by molecular biology, increase the possibilities available for solving the problems surrounding agriculture and the environment, and have the potential to enable man to continue to improve 
his crop plants and provide more food. In situations, as in Europe, where the amount of total food production is sufficient or in surplus, crop improvement through these genetic technologies can contribute to better and more consistent yields and more effective use of resources (land, fertiliser, energy etc.). The increase in solutions provides greater choice for the farmer, the regulator and society in general. If the choice is exercised wisely, then the extra options provided by genetic technologies should allow agriculture to become more environmentally compatible and sustainable.

Risks. At the inception of rDNA technology, it was realised that it was a powerful technology that should be developed carefully. Consequently, following the Asilomar conference in 1973, a series of guidelines were set up in the U.S.A. and other countries to regulate these activities. This was prudent and such prudence is still required in certain areas of the technology. However, in the vast majority of cases additional risk can neither be perceived nor measured. For plants, the US National Academy of Sciences (1987) have concluded that "the risks associated with the introduction of rDNA-engineered organisms are the same in kind as those associated with the introduction of unmodified organisms and organisms modified by other methods." Nevertheless, given the current level of public anxiety, it seems prudent to continue with a step-by-step, case-by-case approach to the release of transformed plants into the environment. In addition, data is being gathered in a number of experiments to evaluate the potential spread of genes out of crop plants into plants growing in the natural environment. This will enable one of the major concerns that of the escape of introduced genes into wild species - to be addressed. However, there is little or no evidence that any major genetic trait introduced into crop plants by conventional methods (including naturally occurring, herbicide tolerance traits) have either "escaped into weeds" or caused a problem by doing so.

Another concern, that is often raised, is that the introduced gene will cause unforseen and dramatic changes in the properties of the crop. This potential risk is not restricted to rDNA derived plants. Every new genotype created by the plant breeder brings about a novel assortment of genes which may have very profound effects. To ensure that these effects are known, all new genotypes undergo a rigorous programme of testing and selection ending, at least in Europe with a minimum of two years of official, independently-regulated trials. In the same way, rDNA plants will also undergo considerable testing before commercial release to ensure their fitness for use. While it is impossible to say that no unforseen effects will occur, this does not alter anything from the existing situation and potential risks will be dealt with in the same way as in existing plant breeding practice.

Public acceptance. A number of factors affect the perception of the public of the acceptability of a new technology. In general these have led to a low percentage of support for biotechnology in surveys of opinion. For example, surveys in Denmark (Borre 1990) suggest that only just over $20 \%$ of those asked support gene technology with about $65 \%$ being neutral.

Some of the factors involve include:

(a) anxiety and fear of science and technology; (b) the activities of critics with many different motives; and (c) the apathy or ineptitude of practitioners of molecular biology in stating their case to the public.

Ignorance of science is an integral part of modern society. Assessments of scientific literacy in the population of Western Nations indicate that it is very low and not 
changing with time (Durant et al. 1989). Ignorance breeds fear. Technology also means change, another uncomfortable process to the majority of people. History shows that new ideas, new technologies and change in general take a considerable time to become accepted. It is pointless to criticise or rail against this attitude. Furthermore, the public's natural reticence has been reinforced in recent years by disasters arising from new technologies - particularly nuclear energy. Scientists and technologists no longer have the trust and reverence they once had. My conclusion is that those who believe in the beneficial balance of plant molecular biology and biotechnology for society at large must make their case to that society. In doing so they must address the genuine fears that society holds for new technologies.

The general public is also being addressed by a range of critics of biotechnology. To win the battle with these critics over the benefits and risks of technology, it is important to understand their motivation. Rarely is this based on strict evaluation of the facts. Firstly, criticism is in itself a business. Large organisations have built up to combat industry and governments. Irrespective of one's opinion of the rights and wrongs of a particular issue, these organisations have the need to perpetuate themselves, to raise funds and to be financially viable. To do this they may target areas that are tangential to their real objectives but which serve to grab the attention and support of the public. Plant biotechnology is a highly visible area of agriculture it therefore provides a 'hook' which can be used to attract attention to other issues. At least some of the critics appear to have as their 'real' target the structure of agriculture in both developed and developing countries and the role of multinational organisations. Although biotechnology probably has little impact on this structure it does provide a platform from which to raise the issue (e.g. see Hobbelink 1991).

Critics are also motivated by political power, particularly the desire to be elected or re-elected. This can be seen in the rise of the Green Party in Germany or in the 'conversion' of the Conservative Government in the U.K., to environmental issues in the late 1980s. In many cases the critical attitude has not arisen by conviction or rational conversion but by the appreciation that such a stance might give an electoral advantage.

The attention of the public is a powerful ego-enhancing drug. Being a critic and portrayer of doom and uncertainty is much more likely to attract attention than a rational presentation of benefits and risks. Such critics are not to be converted by rational arguments - they trade on the emotions of the public and their ego is enhanced by the attention of the media. Bad news and anxiety makes good headlines and sells newspapers - careful explanations of technology and a balanced approach to problems only has limited media value. It is probably impossible and irrelevant to involve oneself in a rational debate of the issues directly with critics motivated in this way.

Many problems such as the structure of agriculture, the economics of the developing world, the growth of the world's population, are so difficult as almost to defy analysis and solution. Nevertheless, many people are desperate to propose a solution and it becomes attractive to grab at easy answers without full consideration as to whether they would help, hinder or be irrelevant. In such circumstances, it is also more comfortable to place the blame elsewhere. In the western world, industry is a convenient 'fall guy'. Under such circumstances plant biotechnology and the industrial firms that practice it are easy targets. This can be seen in recent articles in scientific journals and the popular press. However, if biotechnology was de- 
invented or stopped in its tracks it would not change the problems - they would still exist. It is also difficult to come up with a convincing alternative to the current mixed economic system of the western world. Industry in the western world is in general owned by and responsive to a large number of people and develops in relation to social pressures and the demands of the market. This market is made up of individuals, critics and proponents included, and whether we individually approve of a technology or development or not, it will only proceed if it receives sufficient support of the public. This suggests that the arguments of such critics can be met by encouraging them to face the real and difficult issues underlying some of the above problems.

Because of the issues discussed above, the lack of positive support for biotechnology that has been found in various surveys is not surprising. The position is not improved when scientists make no attempt to explain the technology and its advantages to the public. Many industries have adopted a low profile hoping that the problem will go away. Insufficient knowledge of the science and technology has reached into schools. Where attempts have been made to bring the technology and the benefits that it might bring to the notice of the general public the results have been encouraging. This effort needs to be intensified by both the public and private sector. In other words it is up to all people knowledgeable in the technology, and who believe it will benefit society, to put this view over to the public. Probably the best place to start is in the education system with teachers and pupils. Ingram (in this volume) has made some suggestions how this may be done. Other models exist, but liaison between local education authorities and schools and scientists willing to help explain the technology is an avenue open to most. Unless scientists take the responsibility to inform the public on the nature of molecular biology and how the advances might be used, support for both the science and products of molecular biology will not be forthcoming.

\section{Conclusions}

Industries in the agricultural sector, new venture capital companies and an assortment of other groups have invested a large amount of time and money in plant molecular biology. They have done this for a variety of reasons. Some reasons, such as the promise of a quick and substantial return, have been proven to be unjustified. Virtually no sales have been made so far and satisfactory returns on the investment are unlikely to be achieved for several years. However, others see the possibility for better solutions for agricultural problems and understand that the technology will take time to produce them. In most cases the technical problems are being successfully addressed. What is still uncertain is whether the structure of the regulations under which trade of these products is allowed, the financial structure of the industry, and the acceptance of these products by the public, will result in a favourable balance of return on investment for industry. If this is not forthcoming then industry will withdraw from the area. In the absence of sufficient investment from governments, the increases in genetical potential of our crops to which we have become accustomed will be under threat. This is something that should concern us all. 


\section{References}

Anon. 1990. Guidelines for the labelling of foods produced using genetic modification. Food Advisory Committee. Ministry of Agriculture, Fisheries and Food UK.

Baum, M. \& Appels, R. 1991. The cytogenetic and molecular architecture of chromosome 1R - one of the most widely utilized sources of alien chromatin in wheat varieties. Chromosoma (in press).

Borre, O. 1990. Public opinion on gene technology in Denmark, 1987-1989. Biotech Forum Europe 7, $471-7$.

Crouch, M. 1990. Debating the responsibilities of plant scientists in the decade of the environment. The Plant Cell 2, 275-7.

Durant, J. R., Evans, G. A. \& Thomas, G. P. 1989. The public understanding of science. Nature 340, $11-14$

Gates, P. 1990. Root and branch reformer refuses to yield. The Guardian (Manchester, U.K.) June 8th, 1990 p. 28.

Goldburg, R., Rissler, J., Shand, H. \& Hassebrook, C. 1989. Biotechnology's bitter harvest; a report of the Biotechnology Working Group. Tides Foundation U.S.A.

Hobbelink, H. 1991. Biotechnology and the future of world agriculture. London: Zed Books.

Medawar, P. 1984. The limits of science. Oxford: Oxford University Press.

National Academy of Sciences. 1987. Introduction of recombinant organisms into the environment: key issues. Washington, D.C.: National Academy Press.

Perlak, F. J., Deaton, R. W., Armstrong, T. A., Fuchs, R. L., Sims, S. R., Greenplate, J. T. \& Fischoff, D. A. 1990. Insect resistant cotton plants. Bio/Technology 8, 939-43.

Young, N. D. \& Tanksley, S. D. 1989. RFLP analysis of the size of chromosomal segments retained around the Tm-2 locus of tomato during backcross breeding. Theoretical \& Applied Genetics 77, 353-59. 